\title{
A Remote Sensing and GIS Approach to Study the Long-Term Vegetation Recovery of a Fire-Affected Pine Forest in Southern Greece
}

\author{
Foula Nioti *, Fotios Xystrakis, Nikos Koutsias and Panayotis Dimopoulos \\ Department of Environmental and Natural Resources Management, University of Patras, G. Seferi 2, \\ 30100 Agrinio, Greece; E-Mails: fotios.xystrakis@ gmail.com (F.X.); nkoutsia@ upatras.gr (N.K.); \\ pdimopoulos@upatras.gr (P.D.) \\ * Author to whom correspondence should be addressed; E-Mail: foula.nioti@yahoo.gr; \\ Tel.: +30-264-107-4201; Fax: +30-264-107-4176.
}

Academic Editors: Heiko Balzter and Prasad S. Thenkabail

Received: 9 December 2014 / Accepted: 2 June 2015 / Published: 10 June 2015

\begin{abstract}
Management strategies and silvicultural treatments of fire-prone ecosystems often rely on knowledge of the regeneration potential and long-term recovery ability of vegetation types. Remote sensing and GIS applications are valuable tools providing cost-efficient information on vegetation recovery patterns and their associated environmental factors. In this study we used an ordinal classification scheme to describe the land cover changes induced by a wildfire that occurred in 1983 in Pinus brutia woodlands on Karpathos Aegean Island, south-eastern Greece. As a proxy variable that indicates ecosystem recovery, we also estimated the difference between the NDVI and NBR indices a few months (1984) and almost 30 years after the fire (2012). Environmental explanatory variables were selected using a digital elevation model and various thematic maps. To identify the most influential environmental factors contributing to woodland recovery, binary logistic regression and linear regression techniques were applied. The analyses showed that although a large proportion of the $P$. brutia woodland has recovered 26 years after the fire event, a considerable amount of woodland had turned into scrub vegetation. Altitude, slope inclination, solar radiation, and pre-fire woodland physiognomy were identified as dominant factors influencing the vegetation's recovery probability. Additionally, altitude and inclination are the variables that explain changes in the satellite remote sensing vegetation indices reflecting the recovery potential. Pinus brutia showed a good post-fire recovery potential, especially in parts of the study area with increased moisture availability.
\end{abstract}


Keywords: LANDSAT; vegetation indices; NDVI; logistic regression; Mediterranean; regeneration; wildland fires

\section{Introduction}

Pinus brutia Ten. is an important woody vegetation component in the Eastern Mediterranean, forming usually pure stands [1] that extend from the East Aegean islands and Crete through Turkey and Cyprus to Lebanon, Syria, Iraq, and as far as the northern shores of the Black Sea [2]. It occurs mainly in the semi-arid and sub-humid Mediterranean climatic zones and at various geological substrata and soil types [1], at slightly colder sites in comparison to P. halepensis Miller, with which it may hybridize where the two species come in contact [3]. The P. brutia forests are characterized by the frequent occurrence of fires and the species has evolved numerous adaptations concerning post-fire regeneration, such as enhanced seedling emergence, establishment, and survival [4] alongside rapid growth of seedlings and saplings [1]. This behavior favors potentially rapid tree regeneration and increases the possibility of ecosystems' recovery after a fire incident in the absence of other disturbances during the regeneration process [5].

The vast majority of studies on regeneration of Mediterranean pine ecosystems concerns the related species $P$. halepensis [6,7]; hence, these are restricted to the western Mediterranean region [8] and mostly refer to the initial stages of post-fire regeneration [9-11]. It is generally accepted in the international literature that the regeneration potential of the $P$. halepensis and P. brutia woodlands is adequate under various climatic types, topographic features, parent material, and soil types, provided that all possible human-related factors that might increase seedling mortality, e.g., grazing [7] are excluded from the ecosystem. However, the pine forests' regeneration is also highly dependent on fire recurrence and mean fire frequency [12,13], and is particularly affected by fire intensity and fire or burn severity $[14,15]$. In this sense, maps depicting the spatially explicit fire history of an area, including variables such as fire frequency and fire return interval, are important tools that promote the understanding of processes associated with wildfires (fire ignition and spread) and the assessment of the impacts of wildland fires on landscape dynamics, and support decision-making towards appropriate management practices [16].

The environmental variables that are more frequently correlated with enhanced regeneration and vigorous growth of seedlings of the two pine species, such as temperature, energy, and soil moisture, are strongly associated with resource gradients [17]. Among these, the most commonly tested variables are elevation, temperature, precipitation, slope, aspect and topographic position, distance to unburned patches, bedrock, soil type, various soil parameters, and site quality [7,18-21]. Additionally, some of these variables are also associated with the conditions favoring the fires itself, as reported in many studies and especially as shown in long-term statistics [22]. Occasionally some of these variables can exhibit a dual role in fire risk when fuel build-up and dryness is considered [23] or, as reported in Koutsias et al. [24], when demographic shifts from rural to urban areas may favor fuel conditions that lead to large fires, once a fire has been ignited. In the Mediterranean the ecological adaptations of plants to drought have been associated with the recent fire regime [25]. 
The number of studies focusing on the long-term recovery and resilience of Mediterranean vegetation types after fire, as discussed in Kazanis and Arianoutsou [10], Baeza et al. [17], and Lloret et al. [26] is rather small, when compared with the studies dealing with the short-term post-fire regeneration. This is mainly due to the fact that these ecosystems usually return to their previous state after 10-12 years [9], as well as to the difficulty in analyzing the process of long-term vegetation recovery following wildfires, since the recovery depends on a great variety of biological and environmental factors, as well as on the interactions between them. Nevertheless, the different rates of recovery for each vegetation type and the slower rate for certain forest types [26] lead to a dwarf/low shrub domination of ecosystems in the first months, in agreement with the results of other similar studies $[17,27,28]$. Moreover, long-term changes in landscape are often subjected to socioeconomic factors that can weaken correlations between vegetation types and physical environment [17].

The main objectives of this study are: (a) to identify the environmental parameters that could contribute to the recovery of the $P$. brutia woodlands burned in 1983 at the island of Karpathos (SE-Aegean); and (b) to identify the land cover changes (1982-2009) associated with this fire event. The study implements a remote sensing and GIS approach with LANDSAT satellite images and vegetation indices estimated a few months (1984) and almost 30 years after the fire (2012).
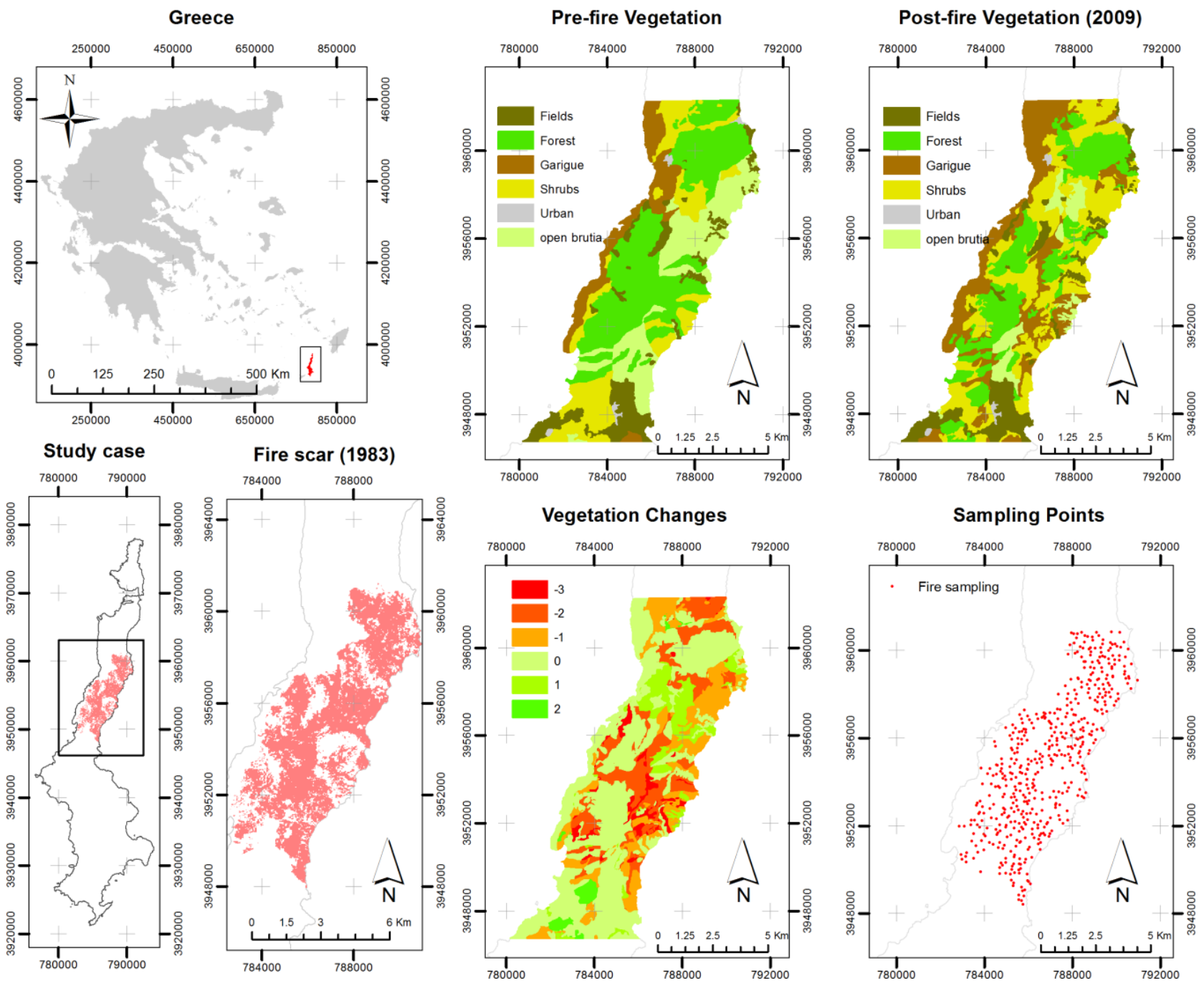

Figure 1. Geographical location and changes between pre- and post-fire land cover. The fire scar and the sampling points are also depicted. 


\section{Study Area}

The study area is located on the island of Karpathos in the east Aegean Sea (Figure 1) where, in 1983 a large wildfire burned 4475 ha of Pinus brutia woodland, according to the Hellenic Forest Service. The fire scar is included in the rectangle $27^{\circ} 7^{\prime} 25.9^{\prime \prime} \mathrm{E}-35^{\circ} 38^{\prime} 12.3^{\prime \prime} \mathrm{N}$ (southwest angle) $27^{\circ} 13^{\prime} 5.6^{\prime \prime} \mathrm{E}-35^{\circ} 45^{\prime} 19.7^{\prime \prime} \mathrm{N}$ (northeast angle) and includes unburned patches within the general burned perimeter (Figure 1). The fire burnt mainly P. brutia stands, though other vegetation types, including phrygana, were also affected.

Karpathos belongs to the Oleo-Ceratonion vegetation formation, which falls within the Thermo-Mediterranean climatic zone [29]. The elevation ranges between 0 and $684 \mathrm{~m}$ above sea level. The island's climate is typically Mediterranean, with the dry period lasting from mid-March to mid-October. According to the data obtained from Karpathos meteorological station (1971-2010), the mean annual precipitation is $386.7 \mathrm{~mm}$, the mean annual temperature is $19.4{ }^{\circ} \mathrm{C}$, the minimum temperature of the coldest month is $0.8^{\circ} \mathrm{C}$, and the maximum temperature of the warmest month is $45{ }^{\circ} \mathrm{C}$. The geological substrata of the island mainly consist of hard limestone and flysch; however, the fire only affected vegetation growing on flysch.

\section{Material and Methods}

\subsection{Creation of the Dependent and Independent Data Sets}

\subsubsection{Burned Land Mapping}

No accurate, detailed map of the area burned was available for the wildfire of 1983. Instead, only a general sketch of the burn perimeter was available and this lacked detailed spatial information, especially for unburned patches within the fire scar perimeter. The spatially explicit mapping of the fire scar including the unburned patches was addressed in the study of [30] using 1984 LANDSAT satellite images. In that study, we corrected the fire scar perimeter using USGS archived LANDSAT multi-temporal satellite data.

\subsubsection{Environmental Explanatory Variables}

To assess the impact of the natural environment on the post-fire recovery of $P$. brutia woodland vegetation, the following variables were considered: altitude, aspect, inclination, geological substrate and soil data, solar radiation, and distance from the hydrographical network. Altitude (meters a.s.1.) was estimated using a digital elevation model (30 m DEM) that was developed from contour lines in ArcGIS software. The DEM also provided the basis for the estimation of slope inclination (degrees) and aspect (degrees). Aspect was then transformed using the equation aspect $=$ cos (aspect in degrees-22.5) in order to avoid its circular character [19]. Geological substrate and soil depth were determined from 1:50,000 geological and soil maps, respectively, obtained from the Ministry of Agriculture. The nearest distance from the hydrographical network $(\mathrm{m})$ was calculated using the $30 \mathrm{~m}$ DEM and the ArcGIS Hydrology Tools. Incoming solar radiation was estimated with the spatial analyst of ArcGIS software, taking into consideration slope inclinations, orientation, and relief shading. Additionally, we estimated the distances of each sampling point from the closest unburned 
site, and the closest unburned pine woodland. All these variables were estimated for each sample point of the study area's sampling design described in Section 3.2.1.

\subsubsection{Pre-Fire and Post-Fire Land Cover Mapping and Changes}

Given the discrepancies between the land cover legends of the available pre- and post-fire land cover maps and the limitations arising from the use of satellite data [31], we developed a classification scheme that minimizes misclassification errors. The classification scheme adopted consists of four land cover classes: (a) dense P. brutia woodland (cover > 25\%); (b) open P. brutia woodland (cover < 25\%); (c) scrubland (with non-significant presence of individual $P$. brutia trees (scattered trees) from the cover-abundance point of view; and (d) phrygana (garrigues) representing sparsely vegetated areas where trees and tall shrubs were absent. This classification scheme was applied to both pre- and post-fire vegetation maps.

To define the pre-fire vegetation, we used a vegetation map derived from extensive field data collected on the island in 1981 [32], LANDSAT satellite images acquired in 1975 (Multi-Spectral Scanner), and LANDSAT satellite images acquired in 1984 (Thematic Mapper) were used to assist photointerpretation, especially in the areas surrounding the fire scar. The satellite data was used as auxiliary information to refine the original vegetation map and harmonize it to the spatial scale of the post-fire land cover map (Figure 1). To create the post-fire vegetation map (Figure 1), we used the CORINE 2000 land cover/use map and satellite data of LANDSAT-5 Thematic Mapper acquired in 2008 and 2009. The final pre- and post-fire vegetation maps were harmonized and transformed into that with the most detailed spatial scale (the post-fire land cover map).

Finally, the pre- and post-fire land cover maps were overlaid to create a third thematic layer that would show changes to the distribution patterns of vegetation before and 26 years after the fire event. The vegetation types were firstly classified in an ordinal sequence assuming that dense $P$. brutia woodland reflects the final, successional ecosystem stage, followed by open P. brutia woodland, scrublands, and phrygana. The post-fire vegetation was also classified according to this ordinal scale. Finally, the "difference" between the pre- and post-fire vegetation classes was estimated in order to create a final map of the vegetation changes within the burned area. An ordinal index was adopted to evaluate the vegetation changes in terms of recovery classes, as shown in Table 1.

Table 1. Ordinal classification scheme of vegetation changes.

\begin{tabular}{ccccc}
\hline \multirow{2}{*}{ Pre-Fire Vegetation } & \multicolumn{4}{c}{ Post-Fire Vegetation } \\
\cline { 2 - 5 } & Dense $\boldsymbol{P}$. Brutia Woodland & Open $\boldsymbol{P}$. Brutia Woodland & Scrubland & Phrygana (Garrigues) \\
\hline Dense $P$. brutia woodland & 0 & -1 & -2 & -3 \\
Open $P$. brutia woodland & 1 & 0 & -1 & -2 \\
Scrubland & 2 & 1 & 0 & -1 \\
Phrygana (garrigues) & 3 & 2 & 1 & 0 \\
\hline
\end{tabular}

\subsubsection{Satellite-Based Vegetation Indices}

Changes in the vegetation indices were estimated from satellite remote sensing data. Specifically, we estimated the Normalized Difference Vegetation Index (NDVI) [33,34], which combines the 
Red-Near Infrared (R-NIR) bi-spectral space and has been applied extensively in studies of remote sensing on forest fires [35] and the Normalized Burn Ratio (NBR) [36,37] for the 1984 and 2012 LANDSAT images. NDVI has been demonstrated as a good discriminator between scorched and non-scorched areas [38,39], although it is sensitive to optical properties of the soil background [40] especially in sparsely vegetated areas [41]. Some NDVI modifications have been developed to minimize soil $[42,43]$ and atmospheric variability $[44,45]$. NBR is a modification of the Normalized Difference Vegetation Index (NDVI) that replaces red with Shortwave Infrared (SWIR), and was originally proposed by Lopez-Garcia and Caselles [46], who underlined the post-fire radiometric changes occurring in the SWIR, as later verified by Koutsias and Karteris [47]. The use of these indices is also justified according to a recent study on the sensitivity of spectral reflectance values to different burn and vegetation ratios by Pleniou and Koutsias [48], who concluded that the NIR and SWIR are the most important channels to estimate the percentage of burned area, whereas the NIR and red channels are the most important to estimate the percentage of vegetation in fire-affected areas [49]. Additionally, Pleniou and Koutsias [50] found that the semi-burned classes are spectrally more consistent with their different fractions of scorched and non-scorched vegetation than the original spectral channels, based on which these indices are estimated.

The application of vegetation indices is a very common approach in remote sensing of burned areas, used to either map fire scars or estimate burn severity since they minimize the effect of exogenous factors and enhance the correlation with the internal vegetation parameters. In a recent study we found that the original spectral channels, based on which these indices are estimated, are sensitive to external vegetation parameters such as the spectral reflectance of the background soil [48]. In such cases, the influence of the soil in the reflectance values is different in the various spectral regions depending on its type.

\subsection{Statistical Analyses}

\subsubsection{Sampling}

A total of 500 points (cases) were randomly selected within the study area. We applied the generalized random-tessellation stratified sampling [51] with a sample size proportional to the area of each class (classification unit). The sampling was performed using the spsurvey library in R [52]. The generalized random-tessellation stratified sampling created a spatial pattern of points that closely resembles the spatial density of the land use/land cover classes. Eleven points that fell within agricultural fields were excluded from the data set, resulting in a final number of 489 points that was used for the cross-tabulation analysis. Additionally, a secondary data set was formed and used in the logistic regression analysis, excluding a small number of sampling points that fell on scrub and phrygana vegetation. In total, 438 points falling on dense and open P. brutia woodland were used to develop the logistic regression model.

Additionally, 88 homogeneous patches were chosen as test areas from the segments created on the high-resolution panchromatic IKONOS imagery. After the application of a segmentation algorithm to the high-resolution panchromatic IKONOS image using the eCognition ${ }^{\circledR}$ Developer software we selected visually the 88 homogeneous patches. The NDVI and NBR differences and environmental 
variables were extracted from each area. The panchromatic component of a high-resolution IKONOS image acquired for the study area in 2012 was segmented using eCognition software to create homogeneous segments (Figure 2) of burnt and unburned patches [53,54].
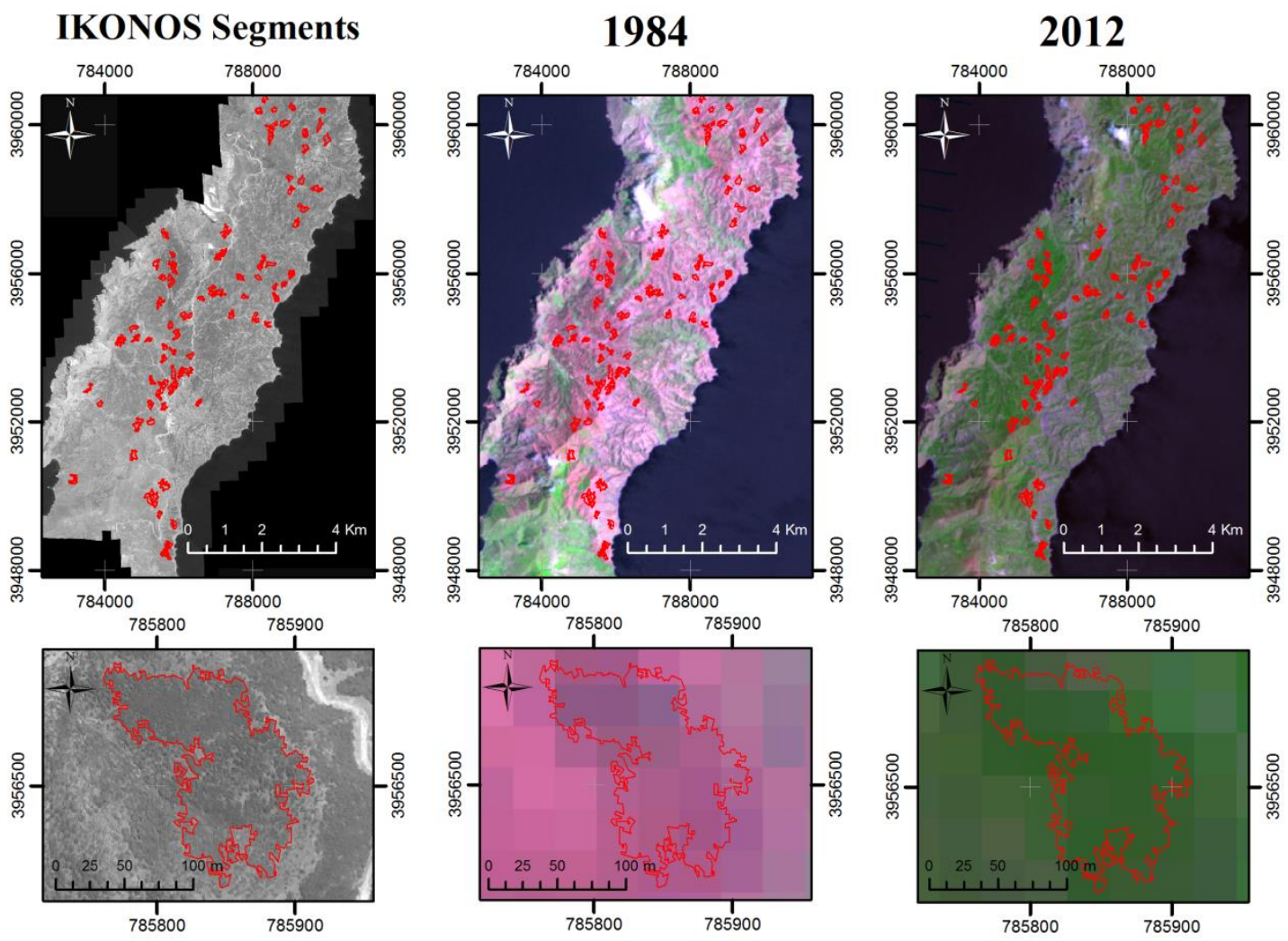

Figure 2. IKONOS segmentation and the burnt areas polygons.

\subsubsection{Cross-Tabulation Analysis}

Cross-tabulation (contingency tables) analysis was applied to detect vegetation cover changes over the examined time period (pre- and post-fire vegetation). The analysis was performed by applying the "gmodels" package in R [52] on the data set including the 489 sampling points. Chi squared test was applied to test the null hypothesis of no effects. The expected values were estimated by the chi-square test and were compared with their respective observed values.

\subsubsection{Logistic Regression}

Forest recovery was analyzed by applying binary logistic regression to the data set, including only those points that fell within pre-fire pine forests. The ordinal recovery classes (Table 1) were expressed as binary variables by attributing the value " 1 " if pine woodland had recovered to its pre-fire state and the value " 0 " if not. Binary logistic regression was then performed to predict the value of a response variable (reference category "recovered" in this study) from the values of a set of environmental explanatory variables $[47,55,56]$. A regression analysis was performed by testing the best model applying the BIC criterion in the "bestglm" package in R [52] including the following continuous variables as predictors: "altitude," "slope," "aspect," "solar radiation," "distance from unburned sites," "distance from unburned P. brutia forest," and the categorical variables "soil depth," "bedrock type," 
and "pre-fire vegetation" (dense or open $P$. brutia stands). The between-variables effects were tested using sequential logistic regression. However, this was not included in the final analysis due to their small contribution to the improvement of the model's predictive power and their significant and high correlation with the "raw" variables. Model performance was tested by means of the area under the receiver operating characteristic (ROC) curve, an equivalent of the concordance index, and was estimated by the "lroc" package in R [52]. The area under the ROC curve is a measure of discrimination and values ranging from 0.7 to 0.8 indicate acceptable discrimination [57]. The Hosmer-Lemeshow goodness of fit test [57] was also applied to determine how well the model fit the data. Density curves of selected explanatory variables of the recovery classes were drawn using the "sm" R package [52] in order to visualize the differences in the distribution of variables between the two recovery classes.

\subsubsection{Changes of Satellite-Based Vegetation Indices}

As a proxy variable that indicates ecosystem recovery, we used the difference between the NDVI and NBR indices just after (1984 - the year after the fire where the burned area signal is still evident in the satellite image) and in 2012. It is assumed that the greater the difference in indices values between these periods, the stronger the indication that a high regeneration rate, or recovery, has been achieved. The distributions of NDVI and NBR indices of burnt and unburned patches were plotted and linear regression analysis was performed between the values of the indices differences and selected environmental variables.

\section{Results}

\subsection{Vegetation Changes-Cross-Tabulation Analysis}

Changes in cover of the different vegetation types occurring from 1981 (two years before the fire) to 2009 (26 years after the fire), are shown in Table 2. The overall changes indicate a decrease in dense woodland (from 54.8\% to 37.4\%) and open woodland (from 34.8\% to 7.8\%). Pinus brutia woodland was accompanied by an increase in scrublands (from $9.8 \%$ to $37.4 \%$ ) and garrigues (from $0.6 \%$ to 17.4\%). Regarding changes within the vegetation types, $58.2 \%$ of the original dense P. brutia woodland was classified as belonging to the same class 26 years after the fire and the chi-square test indicates that this cannot be attributed only to chance. On the other hand, $15.9 \%$ of the original open $P$. brutia woodland was classified as dense woodland, while $52.9 \%$ was found to have transformed into scrubland. The considerably large chi-square contributions of these values indicate that these changes are worthy of further examination. Regarding the original scrublands, $56.2 \%$ and $31.2 \%$ were classified as garrigues and open $P$. brutia woodland, respectively, and the difference between observed and expected values indicate that these changes cannot be attributed solely to chance. The latter change indicates that a large proportion of scrublands had failed to recover 26 years after the fire. However, in a considerable number of shrub-dominated sampling points the fire resulted in canopy removal, which may have promoted $P$. brutia seed germination. 
Table 2. Contingency table of land cover changes 26 years after the fire event.

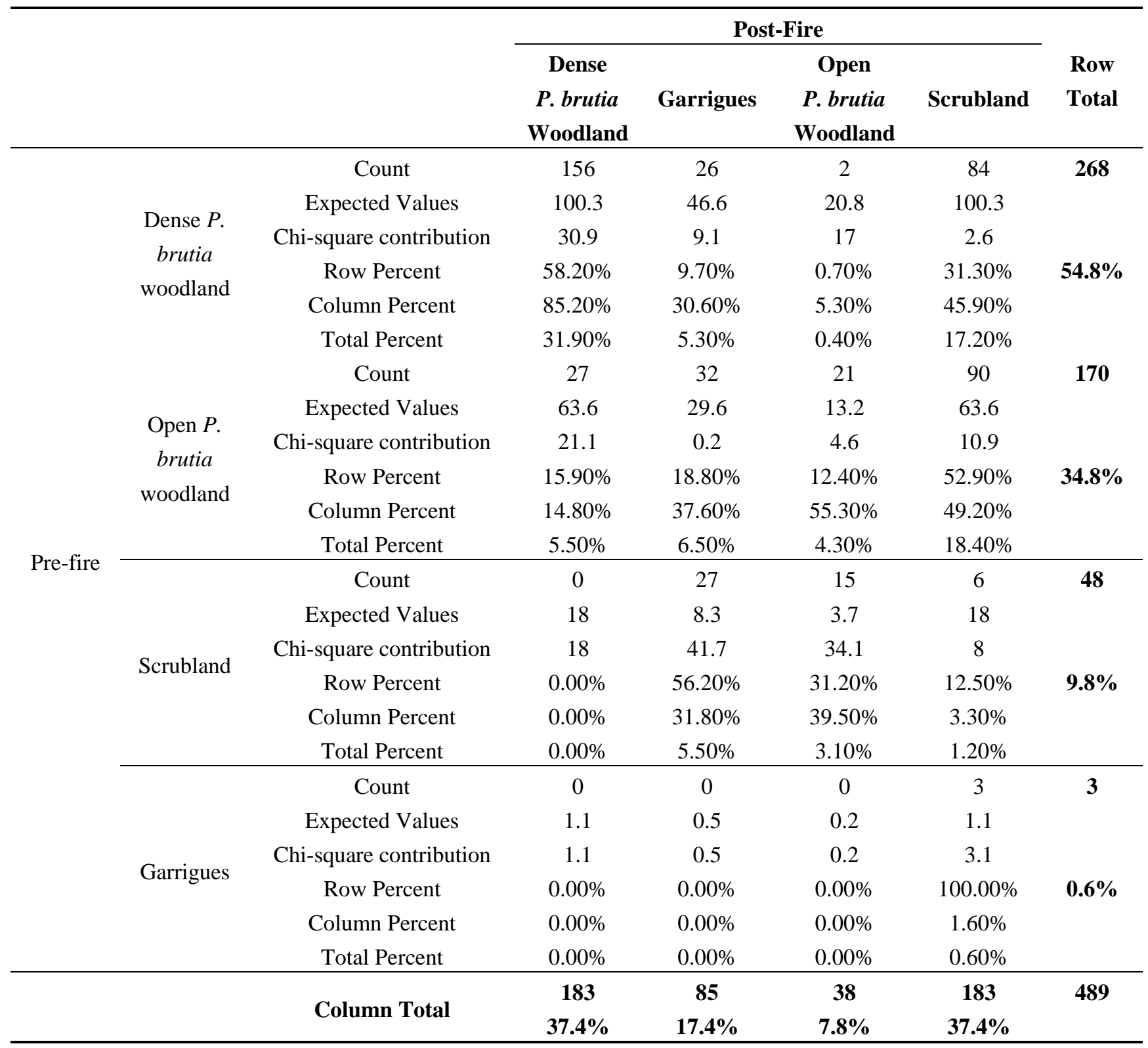

The substantial vegetation recovery observed is also verified by the reduced differences of NDVI and NBR indices between burned and unburned patches 26 years after the fire event (Figure 3).

\subsection{Recovery of Pinus brutia Woodland-Logistic Regression}

The outputs of the binary logistic regression for the recovery of pine woodlands, as also justified by vegetation indices (Figure 3), are presented in Table 3. The reduction in deviance (Table 3) showed that the logistic regression model performs better than the null model, while the Hosmer-Lemeshow test indicated that the model adequately fits the data. The area under the ROC curve is 0.736 (Figure 4a) and indicates its acceptable discrimination effect. It should be mentioned that the residuals from the logistic regression model show some autocorrelation at small lag distances (Figure 4b), which might be to some extent problematic. The model identified five significant explanatory variables that contribute to the odds of woodland recovery, namely "altitude", "slope", "solar radiation", "distance from hydrographic network" and "pre-fire vegetation". Their coefficients indicate that high elevation favors 
the odds for woodland recovery, while steep slopes, high solar radiation, long distances from hydrographic network, and open pre-fire $P$. brutia stands restrict recovery. The density curves of selected environmental variables for the two recovery classes are shown in Figure 5. The figure shows that the variables "incident solar radiation," "altitude" and "slope inclination" exhibit the largest differences between the classes "recovery" and "no recovery".

NBR 1984

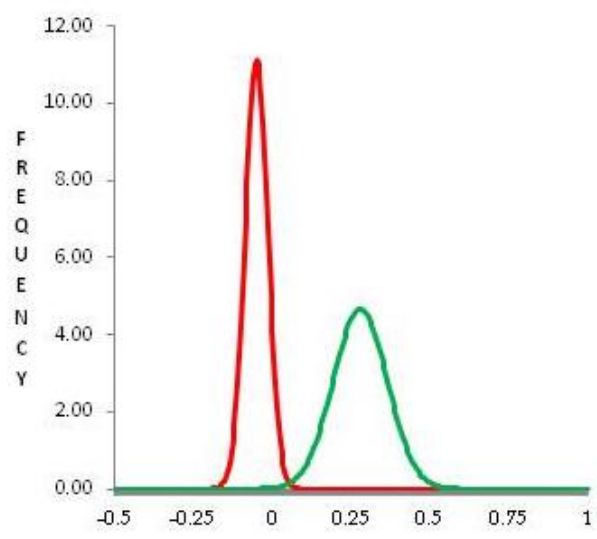

NBR 2012

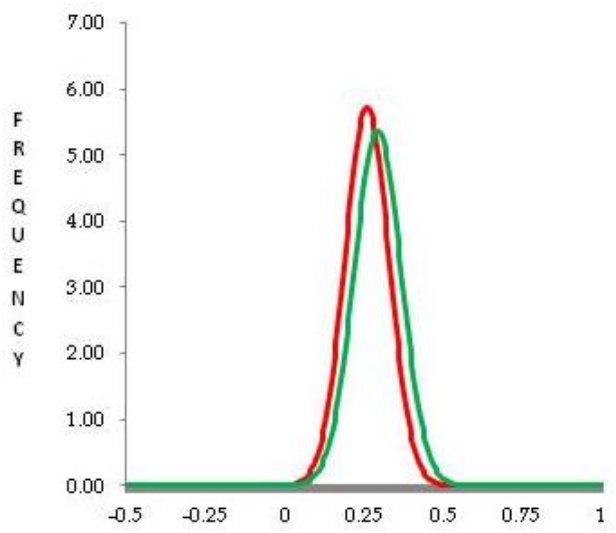

NDVI 1984

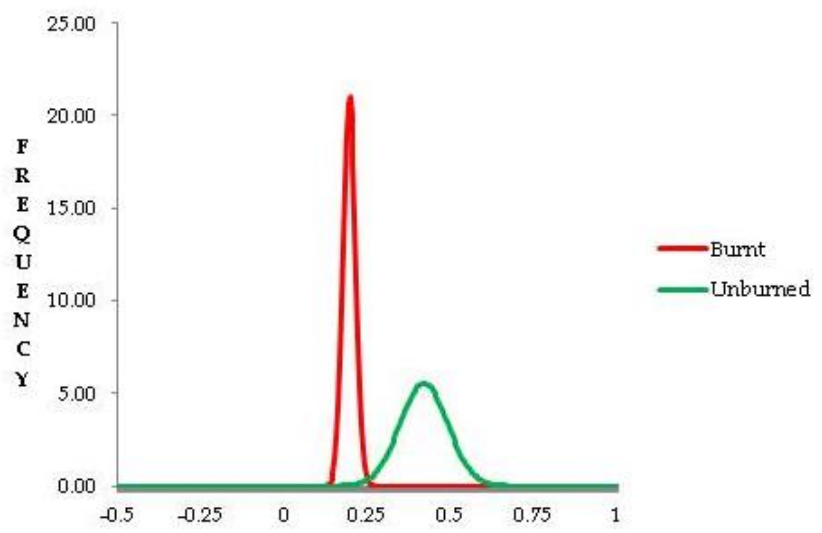

NDVI 2012

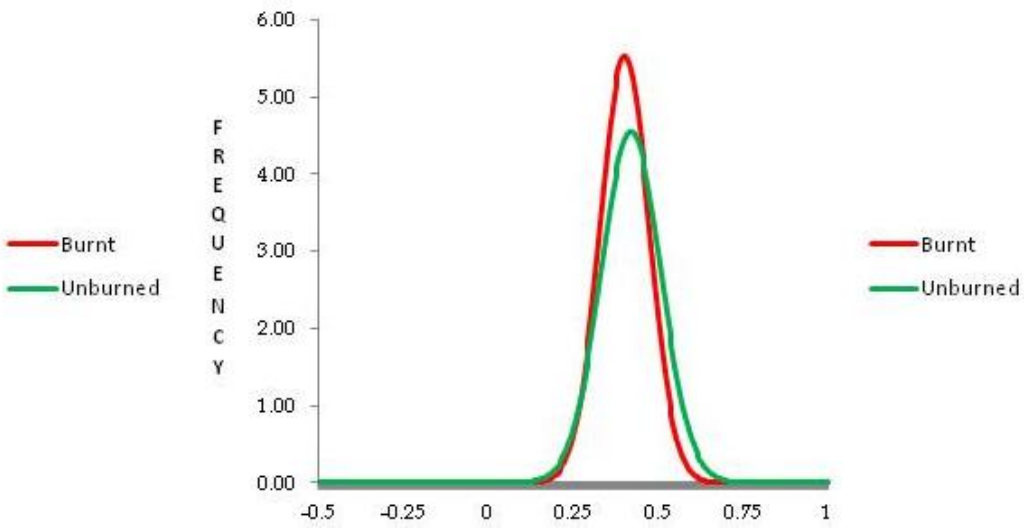

Figure 3. Indication of ecosystem recovery as inferred through the difference between the vegetation rates of NDVI (Normalized Difference Vegetation Index) and NBR (Normalized Burned Ratio) in satellite images from 1984 and 2012.

Table 3. Structure of the binary logistic regression. Hosmer-Lemeshow test outputs: chisq: $7.6117 ; p$-value $=0.472$.

\begin{tabular}{ccccc}
\hline Coefficients & Estimate & Std. Error & $\boldsymbol{z}$-Value & $\operatorname{Pr}(>|\mathbf{z}|)$ \\
\hline (Intercept) & 3.637 & 0.982 & 3.705 & 0.000 \\
altitude & 0.006 & 0.001 & 5.482 & 0.000 \\
slope's inclination & -0.017 & 0.006 & -2.651 & 0.008 \\
incident solar radiation & $-2.73 \mathrm{E}-06$ & $6.91 \mathrm{E}-07$ & -3.945 & 0.000 \\
distance from hydrographic network & -0.002 & 0.001 & -2.604 & 0.009 \\
pre-fire vegetation (open stands) & -0.900 & 0.244 & -3.683 & 0.000 \\
\hline
\end{tabular}


Table 3. Cont.

\begin{tabular}{ccccc}
\hline \multicolumn{7}{c}{ Deviance Residuals } \\
\hline Min & 1Q & Median & 3Q & Max \\
\hline-1.8869 & -1.0249 & -0.4968 & 1.0215 & 2.2247 \\
\hline
\end{tabular}

Null deviance: 605.65 on 437 degrees of freedom

Residual deviance: 522.83 on 432 degrees of freedom

AIC: 534.83

Null/Residual deviance difference: 82.820 (5 degrees of freedom)

Chi-square $p$-value: 0.00000000

Pseudo R-Square (optimistic): 0.41642277

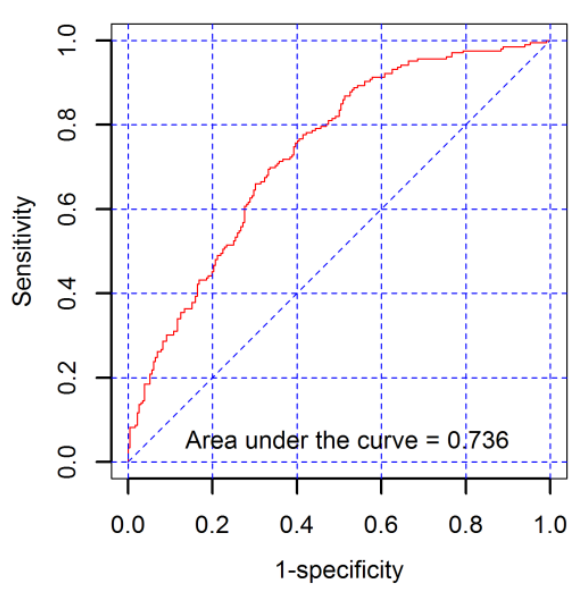

(a)

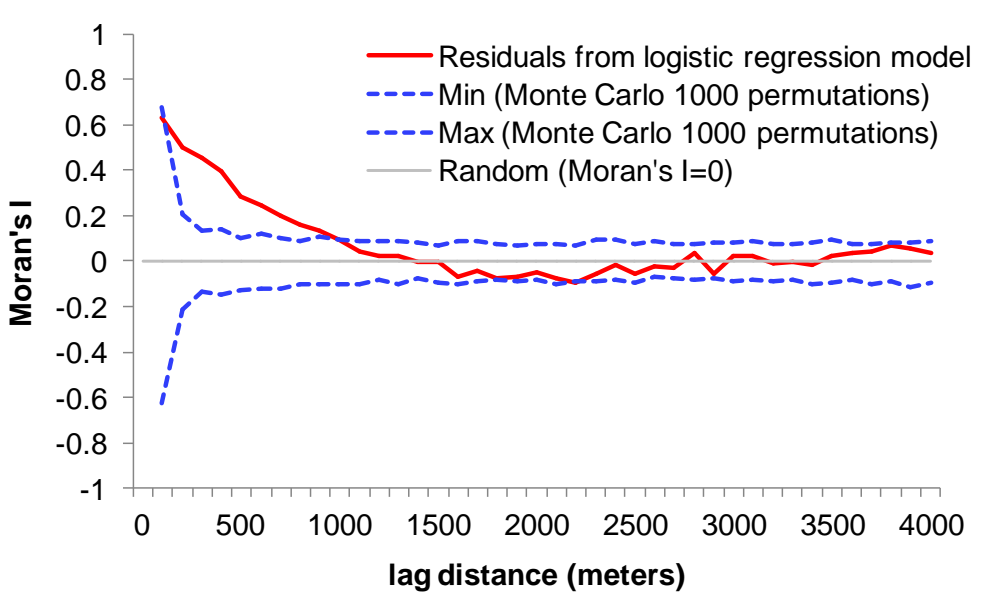

(b)

Figure 4. (a) ROC curve of the logistic regression model. Area under curve value: 0.736, indicating acceptable discrimination and (b) Autocorrelogram based on Moran's I index of spatial autocorrelation.

The overall percentage of correct classifications of the logistic regression was $67.6 \%$ and the McFadden pseudo-square value was 0.137 (Table 4). The correct classification of the class "recovery" was $70.4 \%$ and the respective value for the "no recovery" class was $65.1 \%$. The interpolated recovery probabilities estimated by the logistic regression model are depicted in Figure 6 .

Table 4. Classification tables of logistic regression for all plots. Overall classification: 67.6\%, McFadden pseudo $r$-square: 0.1367 .

\begin{tabular}{ccc}
\hline Actual & \multicolumn{2}{c}{$\begin{array}{c}\text { Predicted } \\
\text { Frequencies }\end{array}$} \\
\hline no recovery & 151 & 61 \\
recovery & 81 & 145 \\
\hline \multicolumn{3}{c}{ Percentages } \\
\hline no recovery & $65.1 \%$ & $29.6 \%$ \\
recovery & $34.9 \%$ & $70.4 \%$ \\
\hline
\end{tabular}




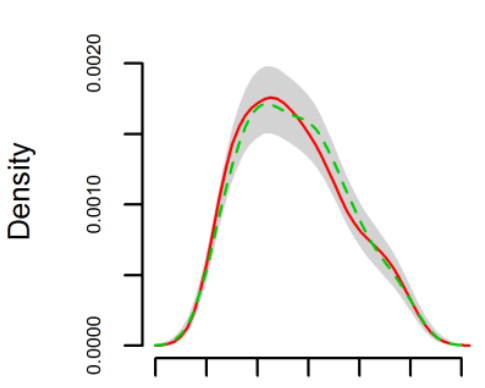

$\begin{array}{llllll}-200 \quad 0 \quad 200 & 400 \quad 600 \quad 800\end{array}$

dist. from hydr. netw

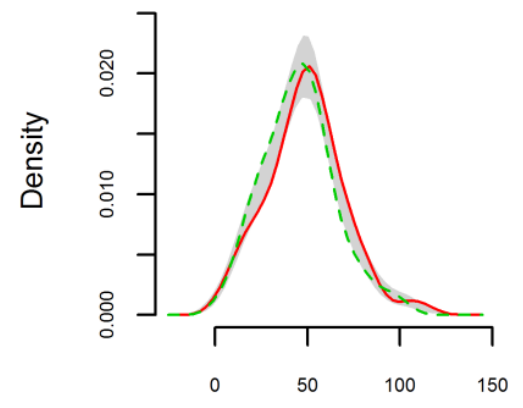

slope's inclination

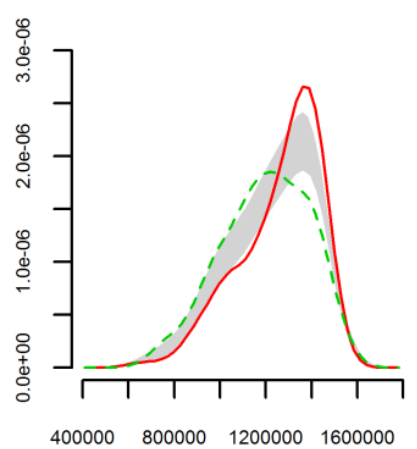

incident solar radiation

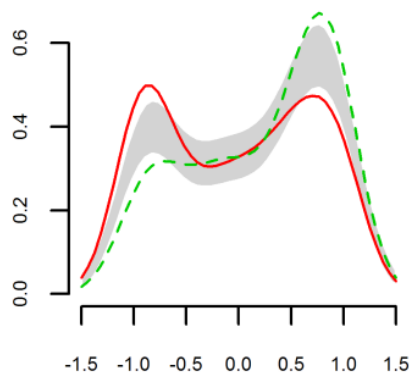

slope's aspect

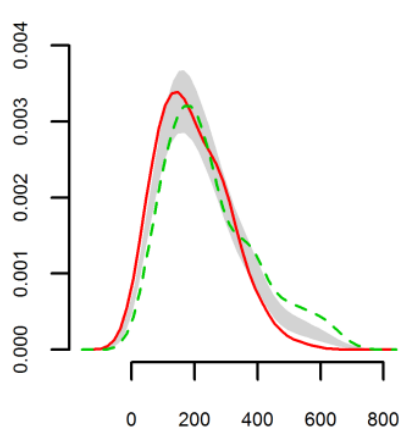

altitude (m a.s.I.)

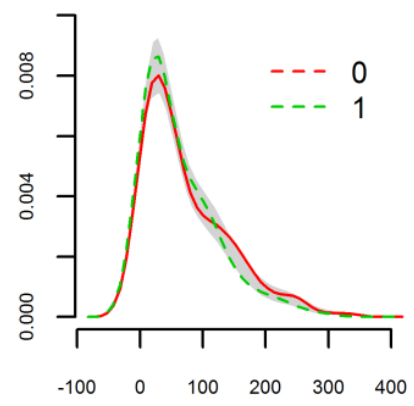

dist. from unburt patches

Figure 5. Estimated density curves of selected environmental variables for each recovery class (0: "no recovery"; 1: "recovery"). Shaded areas represent the reference area of equality. Abbreviations: dist: distance; a.s.l.: above sea level.
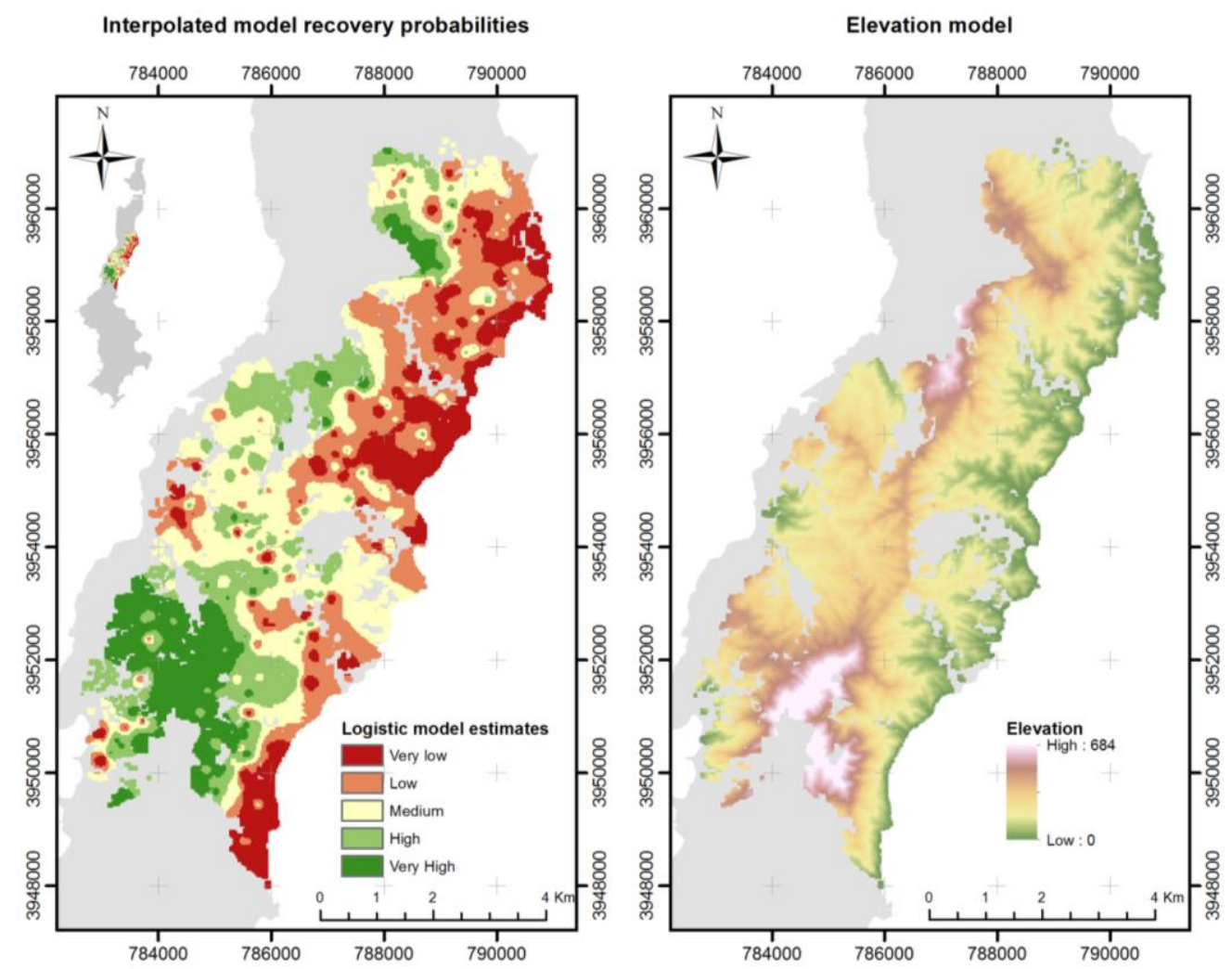

Figure 6. Interpolated (inverse distance weighted) recovery probabilities, as estimated from the logistic regression model, in the study area (left); higher probabilities of recovery are estimated for the areas of higher elevation (right), as predicted from the logistic regression. 


\subsection{Changes in Vegetation Indices-Linear Regression}

Very similar results were also obtained from the linear regression analysis. Altitude and slope inclination were identified as the dominant and significant variables affecting the magnitude of difference of the vegetation indices values (thus recovery) of the selected patches (Table 5). Recovery (estimated as large NDVI and NBR differences) is positively related to altitude, whereas "slope" shows a negative relation to recovery (Figure 7).

Table 5. Recovery affecting factors with regression analysis.

\begin{tabular}{cccc}
\hline Independent Value & Coefficient & Beta (s.c.) & $\boldsymbol{p}$-Value \\
\hline Altitude & 0.124 & 0.352 & 0.003 \\
Slope & 0.105 & -0.324 & 0.006 \\
\hline
\end{tabular}
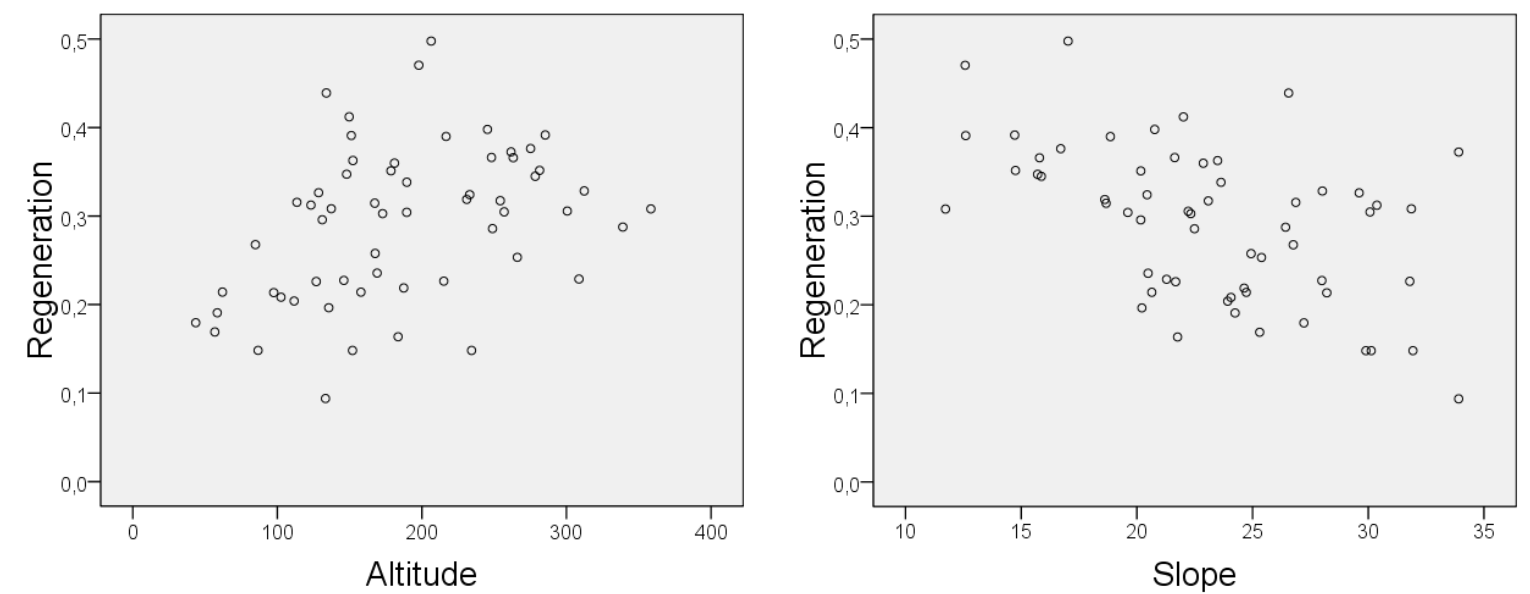

Figure 7. Scatter diagram of regeneration in relation to altitude and slope.

\section{Discussion}

Post-fire vegetation recovery is defined as the ability of an ecosystem or plant community to return to its pre-fire (pre-disturbance) status together with the biotic and abiotic factors related to ecosystem resilience. This field has drawn the attention of many vegetation ecologists [11,17,58,59]. A large number of studies document that thermophilous Mediterranean pine forests, including P. brutia forests, are resilient to fire, mainly due to the high post-fire regeneration ability of the taxon [5]. However, long-term observations on P. brutia recovery patterns are rare. It is well documented that the resilience and regeneration rate of Mediterranean pine forests depend highly on fire re-occurrence [12], provided that the regeneration process is not disrupted by any extreme natural event or any human intervention that may increase seedling mortality, such as grazing [7,60]. Moreover, $P$. halepensis tends to recover and maintain its clear dominance in cases when it forms monospecific stands before the fire event [18].

Our results demonstrate that the landscape of Karpathos Island has been altered by fire, supporting the argument that fire history is indeed a significant landscape modifier in Greece [61]. The reduction of $P$. brutia woodlands (open or dense) is accompanied by an increase in scrubland; however, no conclusions could be extracted on their floristic composition. Similar results have been reported by Lloret et al. [26], with land cover changes, ca. 15 years after the fire events, of $74.3 \%$ and $81.7 \%$ from 
dense and open forests, respectively, to scrublands, while only $16.4 \%$ of the original dense forests retained their land cover class. These results were derived from various land cover types where the dominant tree species was $P$. halepensis. Additionally, extensive transformations from pine forest to scrub vegetation were also reported in the eastern Iberian Peninsula 23 years after a single fire event [17]. Similarly, in central Spain, pine woodlands tend to remain marginally more heterogeneous than scrublands and do not fully recover, or may even disappear from burned areas despite their tendency to increase cover in unburned areas [28]. The low recovery rate of the open woodland may be explained by its limited seed-bank, which cannot support rich regeneration [26].

Secondary successional changes and especially those from phrygana (garrigues) to scrub vegetation can be attributed to land abandonment. Thirty years ago, we noticed that parts that had been mapped in 1981 as garrigues (phrygana) vegetation were actually abandoned terraced fields in which phryganic communities of the Corydothymion capitati vegetation type were actively "invading".

The explanatory ability of the logistic regression could be improved by including additional predictors, as indicated by the significant ( 0.05 level) residual deviances of both models based on the chi-square test. Given data availability, the inclusion of additional explanatory variables that have been proven to play an important role in shaping landscapes and controlling regeneration and recovery patterns could improve the results. Such factors include socioeconomic changes and agricultural land abandonment [62], soil properties and site-quality indices [6,7], fire severity [63,64], or climate-related variables. However, the explanatory power of the simpler model is adequate for descriptive purposes.

The probability of woodland recovery increases with altitude. Altitude, as a topographic factor influencing the recovery of an evergreen forest 30 years after a fire, is discussed in Broncano et al. [18], who document that higher altitudes are more favorable for the recovery of more water-demanding vegetation types. Similar to the present study, altitude is positively related to precipitation changes [65], while altitude is negatively related to changes in air temperature [66]. This combination favors the recovery of pine woodlands as they are more water-demanding vegetation types compared to the scrublands and garrigues of Karpathos Island. Moreover, the effect of altitude on post-fire woodland recovery could be related to the intensity of the human activities (increases with decreasing altitude). The natural vegetation is more affected in the lowest altitudes of the island, due to the high concentration of agriculture, tourist infrastructure, and settlements at these altitudes. Higher altitudes are related to inaccessibility and are usually marginal sites in terms of productivity. When such sites are associated with rock outcrops, steep slopes, and large distances from settlements, active silvopastoralism is not favored and so vegetation is less affected and densification often occurs [67]. These arguments regarding the effect of altitude on woodland regeneration and recovery stress the importance of more thorough research and further discrimination between natural and human-related parameters in explanatory models.

Slope inclination is identified as an important factor defining regeneration potential and recovery ability of the studied P. brutia woodlands. Gentle slopes favor natural regeneration of $P$. halepensis stands in Greece [21] and post-fire regeneration of P. halepensis forests in the Iberian peninsula was, similar to our results, negatively correlated to slope [19]. Steep slopes were found to be negatively related to $P$. halepensis sapling density on various substrates, and were attributed to higher runoff levels inducing aridity [58], as well as to the fact that seeds are more easily washed out from steeper slopes by rain [21]. 
The negative relation between solar radiation and probability of post-fire vegetation recovery is directly related to the effects of solar radiation on evapotranspiration rates and the site's water balance. Low values of incident solar radiation can be crucial for species distribution [68], especially in areas where moisture availability is the main limiting factor, as is the case for the island of Karpathos. In our study area, reduced solar radiation can be associated with better site quality, in terms of moisture availability, resulting in higher regeneration and enhanced growth rates. Tsitsoni et al. [7] proved that the stand density of a $P$. brutia forest, 20 years after a fire event, was higher in the good quality sites, and that site quality mainly depends on soil moisture availability. Water availability, assessed on the basis of incoming radiance, has been identified as the dominant driver of long-term post-fire dynamics, as sites that receive lower radiation values have higher vegetation cover estimates [69].

The negative relationship between pre-fire vegetation (open forest) and vegetation recovery should be attributed to seed availability. Similar results have been reported for the Iberian Peninsula by Pausas et al. [19], where pre-fire stand density was significantly correlated (positively) with post-fire regeneration and enhanced seed availability. Lloret et al. [26] also concluded that open woodlands had low recovery ability. However, pre-fire woodland density can also be related to fuel-load variability, which leads to differences in fire severity that also influence post-fire regeneration [70]. The effect of stand density is more likely restricted to the negative influence due to the lack of seed availability within open stands. No safe conclusion can be drawn concerning the effect of fire severity, since measurements or indices that could be used to estimate fire severity are lacking from the study area.

The negative relationship between distance from the hydrographical network and recovery probability could be related to the position of a pine stand on the hillside (upper, middle, lower altitudes) [21]. Areas situated on lower parts of slopes (i.e., in ravines close to the hydrographical network) have enhanced regeneration potential partly due to increased seed, soil, and ash accumulation as a result of runoff [21], and partly due to reduced direct solar radiation as a result of the shady relief. However, it should be noted that this variable does not always give clear patterns of its effects on regeneration and recovery potential [19]. The other variables examined, i.e., geological substrate and soil depth, did not show significant contributions to the probability of woodland recovery. This could be due to the large scale of the variables' thematic layers, which failed to identify small-scale heterogeneity, or the broad ecological amplitude of P. brutia concerning these environmental factors [1]. Larger scaled geological surveys of the study area could aid the revision of the effect of these variables.

\section{Conclusions}

Post-fire vegetation recovery on the island of Karpathos results from a combination of factors such as pre-fire vegetation, fire history, environmental conditions (climate and landscape structure), and human-induced changes in time and space. It can be argued that when the identified significant variables are interpreted within a combined framework, the effects of site quality, resource availability, and human influence are apparent. This is in general accordance with other studies examining ecosystem resilience [58] or long-term post-fire regeneration [17]. Our combined approach based on remote sensing techniques [31] and geographic information systems does not require large capital investment. Through simple techniques, sites that require special focus and extra effort regarding ecosystems recovery can be identified. Specific management actions to support regeneration or to 
monitor recovery can be focused on parts of extensively burnt areas that exhibit the lowest recovery potential in terms of physical environment. Our results also indirectly demonstrate some methods that can be applicable in post-fire management. The enhanced recovery at low inclinations leads to the consideration of techniques that reduce slope's inclination, as for example the use of logs to build barriers. Such information is important to restoration ecologists and stakeholders, as they can distribute capital and effort explicitly to parts that require human interference.

\section{Acknowledgments}

The authors would like to thank the U.S. Geological Survey for providing the LANDSAT data, as well as Th. Raus, ex-head of the department of outdoor living collections of the Botanical Garden and Botanical Museum Berlin-Dahlem of the Freie Universität Berlin, for his valuable comments concerning patterns and successional stages of the vegetation of the island of Karpathos.

\section{Author Contributions}

Foula Nioti: preparing and analyzing data, writing the manuscript; Fotios Xystrakis: designing the research, analyzing data, and writing the manuscript; Nikos Koutsias: designing the research and writing the manuscript; Panayotis Dimopoulos: writing the manuscript.

\section{Conflicts of Interest}

The authors declare no conflict of interest.

\section{References}

1. Boydak, M. Silvicultural characteristics and natural regeneration of Pinus brutia Ten.-A review. Plant Ecol. 2004, 171, 153-163.

2. Distribution Map of Brutia Pine (Pinus Brutia). Available online: www.euforgen.org (accessed on 5 June 2015).

3. Dounavi, K.; Koutsias, N.; Panetsos, K. Natural interspecific hybridization between Pinus brutia (Ten.) and Pinus halepensis (Mill.), verified by using the logistic regression modeling on morphological characters. For. Genet. 2001, 8, 151-158.

4. Thanos, C.A.; Marcou, S. Post-Fire regeneration in Pinus brutia forest ecosystems of Samos island (Greece): 6 Years after. Acta Oecol. 1991, 12, 633-642.

5. Spanos, I.A.; Daskalakou, E.N.; Thanos, C.A. Postfire, natural regeneration of Pinus brutia forests in Thasos island, Greece. Acta Oecol. Int. J. Ecol. 2000, 21, 13-20.

6. Spanos, I.A.; Radoglou, K.M.; Raftoyannis, Y. Site quality effects on post-fire regeneration of Pinus brutia forest on a Greek island. Appl. Veg. Sci. 2001, 4, 229-236.

7. Tsitsoni, T.; Ganatsas, P.; Zagas, T. Dynamics of postfire regeneration of Pinus brutia Ten. in an artificial forest ecosystem of northern Greece. Plant Ecol. 2004, 171, 165-174.

8. Pausas, J.C.; Llovet, J.; Rodrigo, A.; Vallejo, R. Are wildfires a disaster in the Mediterranean basin?-A review. Int. J. Wildland Fire 2008, 17, 713-723. 
9. Ganatsas, P.; Zagas, T.; Tsakaldimi, A.; Tsitsoni, T. Postfire regeneration dynamics in a Mediterranean type ecosystem in Sithonia, northern Greece: Ten years after the fire. In Proceedings of the 10th MEDECOS Conference, Rhodes, Greece, 25 April-1 May 2004.

10. Kazanis, D.; Arianoutsou, M. Long-term post-fire vegetation dynamics in Pinus halepensis forests of Central Greece: A functional group approach. Plant Ecol. 2004, 171, 101-121.

11. Marzano, R.; Lingua, E.; Garbarino, M. Post-fire effects and short-term regeneration dynamics following high-severity crown fires in a Mediterranean forest. iForest 2012, 5, 93-100.

12. Diaz-Delgado, R.; Lloret, F.; Pons, X.; Terradas, J. Satellite evidence of decreasing resilience in Mediterranean plant communities after recurrent wildfires. Ecology 2002, 83, 2293-2303,

13. Ganatsas, P.; Daskalakou, E.; Paitaridou, D. First results on early post-fire succession in an Abies cephalonica forest (Parnitha National Park, Greece). iForest 2012, 5, 6-12.

14. Martínez-Sánchez, J.J.; Marín, A.; Herranz, J.M.; Ferrandis, P.; De las Heras, J. Effects of high-temperatures on germination of Pinus halepensis Mill and P. pinaster Aiton subsp. pinaster seeds in Southeast Spain. Vegetatio 1995, 116, 69-72.

15. Núñez, M.R.; Calvo, L. Effect of high temperatures on seed germination of Pinus sylvestris and Pinus halepensis. For. Ecol. Manag. 2000, 131, 183-190.

16. Pleniou, M.; Xystrakis, F.; Dimopoulos, P.; Koutsias, N. Maps of fire occurrence-Spatially explicit reconstruction of recent fire history using satellite remote sensing. J. Maps 2013, 8, 499-506.

17. Baeza, M.J.; Valdecantos, A.; Alloza, J.A.; Vallejo, V.R. Human disturbance and environmental factors as drivers of long-term post-fire regeneration patterns in Mediterranean forests. J. Veg. Sci. 2007, 18, 243-252.

18. Broncano, M.J.; Retana, J.; Rodrigo, A. Predicting the recovery of Pinus halepensis and Quercus ilex forests after a large wildfire in northeastern Spain. Plant Ecol. 2005, 180, 47-56.

19. Pausas, J.G.; Ribeiro, E.; Vallejo, R. Post-Fire regeneration variability of Pinus halepensis in the eastern Iberian Peninsula. For. Ecol. Manag. 2004, 203, 251-259.

20. Buhk, C.; Gotzenberger, L.; Wesche, K.; Gomez, P.S.; Hensen, I. Post-fire regeneration in a Mediterranean pine forest with historically low fire frequency. Acta Oecol. 2006, 30, 288-298.

21. Tsitsoni, T. Conditions determining natural regeneration after wildfires in the Pinus halepensis (Miller, 1768) forests of Kassandra peninsula (North Greece). For. Ecol. Manag. 1997, 92, 199-208.

22. Koutsias, N.; Xanthopoulos, G.; Founda, D.; Xystrakis, F.; Nioti, F.; Pleniou, M.; Mallinis, G.; Arianoutsou, M. On the relationships between forest fires and weather conditions in Greece from long-term national observations (1894-2010). Int. J. Wildland Fire 2013, 22, 493-507.

23. Xystrakis, F.; Kallimanis, A.S.; Dimopoulos, P.; Halley, J.M.; Koutsias, N. Precipitation dominates fire occurrence in Greece (1900-2010): Its dual role in fuel build-up and dryness. Nat. Hazards Earth Syst. Sci. 2014, 14, 21-32.

24. Koutsias, N.; Martínez-Fernández, J.; Allgower, B. Do factors causing wildfires vary in space? Evidence from geographically weighted regression. GISci. Remote Sens. 2010, 47, 221-240.

25. Sarris, D.; Koutsias, N. Ecological adaptations of plants to drought influencing the recent fire regime in the Mediterranean. Agric. For. Meteorol. 2014, 184, 158-169.

26. Lloret, F.; Calvo, E.; Pons, X.; Diaz-Delgado. R. Wildfires and landscape patterns in the Eastern Iberian peninsula. Landsc. Ecol. 2002, 17, 745-759. 
27. Pérula, V.G.; Cerrillo, R.M.N.; Rebolloo, P.F.; Murillo, G.V. Postfire regeneration in Pinus pinea L. and Pinus pinaster Aiton in Andalucia (Spain). Environ. Manag. 2003, 31, 86-99.

28. Viedma, O.; Moreno, J.M.; Rieiro, I. Interactions between land use/land cover change, forest fires and landscape structure in Sierra de Gredos (Central Spain). Environ. Conserv. 2006, 33, 212-222.

29. Xystrakis, F.; Koutsias, N. Differences of fire activity and their underlying factors among vegetation formations in Greece. iForest 2013, 6, 132-140.

30. Nioti, F.; Dimopoulos, P.; Koutsias, N. Correcting the fire scar perimeter of a 1983 wildfire using USGS-archived Landsat satellite data. GISci. Remote Sens. 2011, 48, 600-613.

31. Corona, P.; Lamonaca, A.; Chirici, G. Remote sensing support for post fire forest management. iForest 2008, 1, 6-12.

32. Raus, T.; Nioti, F.; Koutsias, N.; Dimopoulos, P. Ecology and mapping of post-fire recovery of Pinus brutia forests: A case study in the island of Karpathos, Greece. In Frontiers of Vegetation Science-An Evolutionary Angle; Mucina, L., Kalwij, J.M., Smith, V.R., Chytry, M., White, P.S., Gilliers, S.S., Pillar, V.D., Zobel, M., Sun, I.-F., Eds.; Keith Phillips Images: Somerset West, South Africa, 2008; pp. 149-150.

33. Kriegler, F.; Malila, W; Nalepka, R.; Richardson, W. Preprocessing transformations and their effects on multispectral recognition. In Proceedings of the Sixth International Symposium on Remote Sensing of Environment, Ann Arbor, MI, USA, 13-16 October 1969.

34. Rouse, J.; Hass, R; Schell, J.; Deering, D. Monitoring vegetation systems in the Great Plains with ERTS. Remote Sens. Environ. 1973, 44, 117-126.

35. Viedma, O.; Melia, J.; Segarra, D.; Garcia-Haro, J. Modeling rates of ecosystem recovery after fires by using Landsat TM data. Remote Sens. Environ. 1997, 61, 383-398.

36. Key, C.H.; Benson, N.C. Measuring and remote sensing of burn severity: The CBI and NBR. In Proceedings of the Joint Fire Science Conference and Workshop, Boise, ID, USA, 15-17 June 1999.

37. Key, C.H.; Benson, N.C. FIREMON-Landscape assessment. In FIREMON: Fire Effects Monitoring and Inventory System; Lutes, D.C., Keane, R.E., Caratti, J.F., Key, C.H., Benson, N.C., Sutherland, S., Gangi, L.J., Eds.; USDA Forest Service, Rocky Mountain Research Station: Ogden, UT, USA, 2006; pp. LA 1-51.

38. Chuvieco, E.; Martin, M.; Palacios, A. Assessment of different spectral indices in the red-near-infrared spectral domain for burned land discrimination. Int. J. Remote Sens. 2002, 23, 5103-5110.

39. Stroppiana, D.; Boschetti, M.; Zaffaroni, P.; Brivio, P.A. Analysis and interpretation of spectral indices for soft multicriteria burned-area mapping in Mediterranean regions. IEEE Geosci. Remote Sens. Lett. 2009, 6, 499-503.

40. Baret, F.; Guyot, G. Potentials and limits of vegetation indices for LAI and APAR assessment. Remote Sens. Environ. 1991, 35, 161-173.

41. Purevdorj, T.; Tateishi, R.; Ishiyama, T.; Honda, Y. Relationships between percent vegetation cover and vegetation indices. Int. J. Remote Sens. 1998, 19, 3519-3535.

42. Huete, A. A soil-adjusted vegetation index (SAVI). Remote Sens. Environ. 1988, 25, 295-309.

43. Qi, J.; Chehbouni, A.; Huete, A.; Kerr, Y.; Sorooshian, S. A modified soil adjusted vegetation index. Remote Sens. Environ. 1994, 48, 119-126. 
44. Kaufman, Y.; Tanre, D. Atmospherically Resistant Vegetation Index (ARVI) for EOS-MODIS. IEEE Trans. Geosci. Remote Sens. 1992, 30, 261-270.

45. Pinty, B.; Verstraete, M. GEMI: A nonlinear index to monitor global vagetation from satellites. Vegetatio 1992, 101, 15-20.

46. Lopez Garcia, M.J.; Caselles, V. Mapping burns and natural reforestation using Thematic Mapper data. Geocarto Int. 1991, 6, 31-37.

47. Koutsias, N.; Karteris, M. Burned area mapping using logistic regression modeling of a single post-fire Landsat-5 Thematic Mapper image. Int. J. Remote Sens. 2000, 21, 673-687.

48. Pleniou, M.; Koutsias, N. Sensitivity of spectral reflectance values to different burn and vegetation ratios: A multi-scale approach applied in a fire affected area. ISPRS J. Photogramm. Remote Sens. 2013, 79, 199-210.

49. Pleniou, M.; Koutsias, N. Relationships between vegetation indices and different burn and vegetation ratios. A multi-scale approach applied in a fire affected area. In Proceedings of the 1st International Conference on Remote Sensing and Geoinformation of the Environment, Paphos, Cyprus, 8-10 April 2013.

50. Pleniou, M.; Koutsias, N. Sensitivity of vegetation indices to different burn and vegetation ratios using LANDSAT-5 satellite data. In Proceedings of the 1st International Conference on Remote Sensing and Geoinformation of the Environment, Paphos, Cyprus, 8-10 April 2013.

51. Stevens, D.L.; Olsen, A.R. Spatially balanced sampling of natural resources. J. Am. Stat. Assoc. 2004, 99, 262-278.

52. R Development Core Team. R: A Language and Environment for Statistical Computing; $\mathrm{R}$ Development Core Team: Vienna, Austria, 2011.

53. Mallinis, G.; Koutsias, N.; Tsakiri-Strati, M.; Karteris, M. Object-Based classification using Quickbird imagery for delineating forest vegetation polygons in a Mediterranean test site. ISPRS J. Photogramm. Remote Sens. 2008, 63, 237-250.

54. Koutsias, N.; Mallinis, G.; Pleniou, M.; Voukelatou, I.; Paschali, T.; Dimopoulos, P. Object-Based classification using a synergy of high spatial (IKONOS) and high spectral (ASTER) satellite data in a rural NATURA 2000 deltaic area. In Proceedings of the 2nd International Conference on Space Technology, Athens, Greece, 15-17 September 2011.

55. Vilar del Hoyo, L.; Martín Isabel, M.; Martínez Vega, F. Logistic regression models for human-caused wildfire risk estimation: Analysing the effect of the spatial accuracy in fire occurrence data. Eur. J. For. Res. 2010, doi:10.1007/s10342-011-0488-2.

56. Vasconcelos, M.J.P.; Silva, S.; Tome, M.; Alnim, M.; Pereira, J.M.C. Spatial prediction of fire ignition probabilities: Comparing logistic regression and neural networks. Photogramm. Eng. Remote Sens. 2001, 67, 73-81.

57. Hosmer, D.W.; Lemeshow, S. Applied Logistic Regression, 2nd ed.; Wiley: New York, NY, USA, 2000.

58. Arianoutsou, M.; Koukoulas, S.; Kazanis, D. Evaluating post-fire forest resilience using GIS and multi-criteria analysis: An example from Cape Sounion national park, Greece. Environ. Manag. 2011, 47, 384-397.

59. Gracia, M.; Retana, J.; Roig, P. Mid-Term successional patterns after fire of mixed pine-oak forests in NE Spain. Acta Oecol. Int. J. Ecol. 2002, 23, 405-411. 
60. Thanos, C.A.; Daskalakou, E.N.; Nikolaidou, S. Early post-fire regeneration of a Pinus halepensis forest on Mount Parnis, Greece. J. Veg. Sci. 1996, 7, 273-280.

61. Arianoutsou, M. Landscape changes in Mediterranean ecosystems of Greece: Implications for fire and biodiversity issues. J. Mediterr. Ecol. 2001, 2, 165-178.

62. Romero-Calcerrada, R.; Perry, G.L.W. The role of land abandonment in landscape dynamics in the SPA Encinares del rio Alberche y Cofio, Central Spain, 1984-1999. Landsc. Urban Plan. 2004, 66, 217-232.

63. Keeley, J.E.; Bond, W.J.; Bradstock, R.A.; Pausas, J.G.; Rundel, P.W. Fire in Mediterranean Ecosystems-Ecology, Evolution and Management; Cambridge University Press: New York, NY, USA, 2011; p. 515.

64. Escuin, S.; Navarro, R.; Fernández, P. Fire severity assessment by using NBR (Normalized Burn Ratio) and NDVI (Normalized Difference Vegetation Index) derived from LANDSAT TM/ETM images. Int. J. Remote Sens. 2007, 29, 1053-1073.

65. Gouvas, M.; Sakellariou, N.; Xystrakis, F. The relationship between altitude of meteorological stations and average monthly and annual Precipitation. Stud. Geophys. Geod. 2009, 53, 557-570.

66. Gouvas, M.; Sakellariou, N. On the estimation of the monthly and annual values of mean maximum and minimum air temperatures over Greece. In Proceedings of the 6th Hellenic Conference in Meteorology Climatology and Atmospheric Physics, Ioannina, Greece, 25-28 September 2002.

67. Röder, A.; Udelhoven, T.; Hill, J.; del Barrio, G.; Tsiourlis, G. Trend analysis of Landsat-TM and -ETM+ imagery to monitor grazing impact in a rangeland ecosystem in Northern Greece. Remote Sens. Environ. 2008, 112, 2863-2875.

68. Bennie, J.; Huntley, B; Wiltshire, A.; Hill, M.O.; Baxter, R. Slope, aspect and climate: Spatially explicit and implicit models of topographic microclimate in chalk grassland. Ecol. Model. 2008, 216, 47-59.

69. Röder, A.; Hill, J.; Duguy, B.; Alloza, J.A.; Vallejo, R. Using long time series of Landsat data to monitor fire events and post-fire dynamics and identify driving factors. A case study in the Ayora region (eastern Spain). Remote Sens. Environ. 2008, 112, 259-273.

70. Pausas, J.G.; Ouadah, N.; Ferran, A.; Gimeno, T; Vallejo, R. Fire severity and seedling establishment in Pinus halepensis woodlands, eastern Iberian Peninsula. Plant Ecol. 2003, 169, 205-213.

(C) 2015 by the authors; licensee MDPI, Basel, Switzerland. This article is an open access article distributed under the terms and conditions of the Creative Commons Attribution license (http://creativecommons.org/licenses/by/4.0/). 